ORIGINAL ARTICLE

\title{
Personality functioning: the influence of stature
}

\author{
F Ulph, P Betts, J Mulligan, R J Stratford
}

Arch Dis Child 2004;89:17-21. doi: 10.1136/adc.2002.010694

See end of article for authors' affiliations ....................

Correspondence to: Dr R Strafford, Department of Psychology, University of Southampton, Highfield, Southampton SO17 1BJ, UK;

R.J.Stratford@soton.ac.uk

Accepted 2 April 2003
Background: The Wessex Growth Study has monitored the psychological development of a large cohort of short normal and average height control participants since school entry.

Aims: To examine the effect of stature on their personality functioning now that they are aged 18-20 years.

Methods: This report contains data from 48 short normal and 66 control participants. Mean height SD score at recruitment was: short normals -2.62 SD, controls -0.22 SD. Final height SD score was: short normals -1.86 , controls 0.07 . The Adolescent to Adult Personality Functioning Assessment (ADAPFA) measures functioning in six domains: education and employment, love relationships, friendships, coping, social contacts, and negotiations.

Results: No significant effect of recruitment height or final height was found on total ADAPFA score or on any of the domain scores. Socioeconomic status significantly affected total score, employment and education, and coping domain scores. Gender had a significant effect on total score, love relationships, coping, and social contacts domain scores. Salient aspects of daily living for this sample were identified from the interviews (prevalence\%): consuming alcohol (94\%), further education (63\%), love relationships $(55 \%)$, current drug use (29\%), experience of violence (28\%), parenthood (11\%), and unemployment $(9 \%)$. Stature was not significantly related to behaviour in any of these areas.

Conclusions: Despite previously reported links between short stature and poorer psychosocial adaptation, no evidence was found that stature per se significantly affected the functioning of the participants in these areas as young adults.
$\mathrm{T}$ he possibility of treating short "normal" children following the creation of biosynthetic growth hormone in 1985 initiated the debate as to whether short stature per se constitutes a disability for which medical treatment is suitable. ${ }^{1-4}$ Treatment might be considered to be favourable if short stature was associated with poorer psychosocial adjustment, but without evidence suggesting this is so, any treatment must be seen as cosmetic. ${ }^{5}$

The psychosocial effects of short stature have been studied for decades producing a wealth of information concerning how short stature may affect children and adults. ${ }^{5-9}$ The literature suggests that adults of short stature are more likely to experience difficulties in the areas of education, employment, love relationships, and friendships. ${ }^{9-14}$ Findings, however, have been inconsistent and there is very little information relating to young adults. As young adulthood is possibly one of the most formative developmental phases, this lack of information gives reason for concern. In addition, much of the previous research has been flawed by methodological weaknesses, such as cross sectional designs, mixed diagnostic groups, and clinical samples. ${ }^{15}$

The Wessex Growth Study is a prospective longitudinal community based study that has followed the physical and psychosocial development of short normal participants and their average height controls from school entry. ${ }^{16}$ Results from previous phases of the study have challenged the perception that childhood short stature is associated with social and psychological disadvantage. ${ }^{17}{ }^{18}$ In the current phase the participants were interviewed when they were aged between 18 and 20 years to assess the influence of childhood and adult height on personality functioning. The aims were to assess whether short stature identified at the age when height screening is now being recommended affects any of the developmental pathways to adulthood and to provide the growth specialist faced with a short normal child a contemporary commentary on psychological outcome.

\section{METHODS}

The participants in the Wessex Growth Study were initially recruited at school entry and have had height and weight measurements taken regularly since. Two previous reports have been made on psychological functioning at age 7-9 years ${ }^{16}$ and $11-13$ years. ${ }^{18}$ This paper reports on assessments made when they were 18-20 years of age.

The participants were interviewed using a standard interview schedule-the Adolescent to Adult Personality Functioning Assessment (ADAPFA)—which measures social and interpersonal role performance in six domains: education and employment, love relationships, friendships, coping, social contacts, and negotiations. ${ }^{19}$ These are all developmental areas in which it has been shown in the literature that people with short stature may have difficulties. The domains are scored using an age related framework resulting in six domain scores between 0 and 5 with higher scores indicating poorer functioning. The domain scores can be aggregated to form a composite ADAPFA score, with a maximum of 30 and a cut off score of 16 above which functioning is regarded as dysfunctional. ${ }^{20}$ The ADAPFA is a development from the Adult Personality Functioning Assessment (APFA) which in research with adults has shown reliability and construct validity. ADAPFA, adapted to focus on the adolescent to adult transition, has been used in a recent follow up of interpersonal and social role performance in young people who experienced cancer in childhood, a study comparable in scope to the present one.

ADAPFA scoring, which provides information on the level of functioning within its six domains, is based on material

Abbreviations: ADAPFA, Adolescent to Adult Personality Functioning Assessment; APFA, Adult Personality Functioning Assessment; C, control; SES, socioeconomic status; SN, short normal 
Table 1 Derivation of aspects of daily living

\begin{tabular}{ll}
\hline ADAPFA domain & Aspect of daily living \\
\hline Background questions & $\begin{array}{l}\text { Drug taking behaviours } \\
\text { Drinking frequency }\end{array}$ \\
Education and employment & $\begin{array}{l}\text { Further education } \\
\text { Employment }\end{array}$ \\
Love relationships & Relationships \\
Sexual contacts & Parenthood \\
\hline
\end{tabular}

from interviews lasting approximately an hour. Transcripts of interviews carried out in this study were further utilised to afford a more qualitative analysis of the participants' life experience as emerging adults. This thematic analysis identified a set of discrete "marker" behaviours within each ADAPFA domain, which have been labelled collectively as "aspects of daily living" (see table 1). These relate to education received beyond school, employment status, relationships with a partner, parenthood, drug taking, drinking, and involvement with violence. Simple counts were made of the numbers of participants in each group who confirmed the behaviour during their interview.

\section{Participants}

At the beginning of this phase of the research $61 \%$ of the original participants were still available to the study ( 76 short normal (SN) and 94 control (C)). This reduction in sample size was due to attrition ${ }^{18}$ and an earlier recruitment of some of the participants into a separate study investigating the psychological effects of GH treatment. ${ }^{21}$ This treatment was offered to the very shortest of the total sample (less than -2 SD score for height), but allocation was random-by lot-leaving no systematic effect on the representativeness of the remainder. Of these remaining 170 participants, 114 (48 SN, 66 C) were interviewed (67\%). Assessments were made to examine whether these 114 participants were representative of the available sample for interview (see table 2 ).

At initial recruitment, two distinct groups were selected: short normal participants, with height below the 2nd centile according to the 1990 UK Growth Standards ${ }^{22}$ and age and gender matched average height controls. ${ }^{17}$ During the course of the Wessex Growth Study there has been variation in participants' height SD scores in both the short and average height control groups in some cases to such a degree that there is considerable overlap of the two groups' final height SD scores (fig 1). The ADAPFA scores and the aspects of daily living results were therefore analysed to examine the effect of both recruitment and final height.

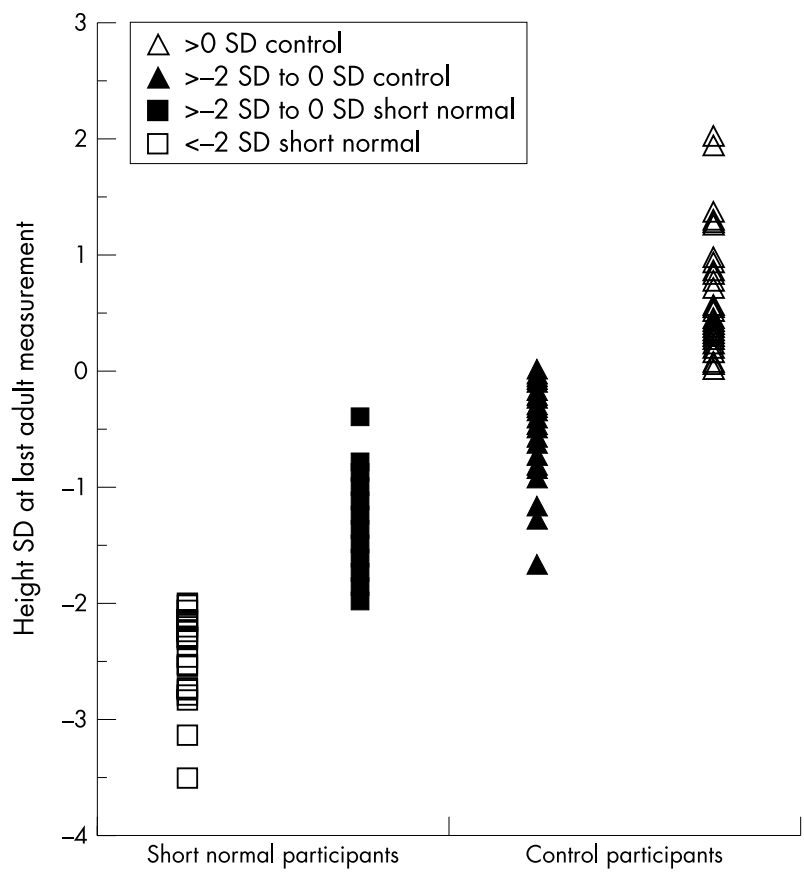

Figure 1 Height at final measurement for the participants involved in study in SD.

The effect of final height was examined by reallocating the participants into three height groups based on their final height centile: $<2$ nd centile $(\mathrm{n}=19)$, 2nd-50th centile $(n=61)$, and $>50$ th centile $(n=34)$. Since the middle group (2nd-50th centile) consisted of both initial short normal and average height participants, the outcome variables for these participants were compared, and homogeneity was shown.

\section{Analyses}

To control for the potential effects of both gender ${ }^{25}$ and socioeconomic status (SES) $)^{23}$ on personality functioning ${ }^{26}{ }^{27}$ group mean differences in the total and six domain ADAPFA scores between height groups were examined using multivariate analysis of covariance (MANCOVA). In this way, differences between the height groups associated with gender (with males typically taller), and with SES (with the more affluent groups typically taller) would be controlled for these two critical independent variables. Gender was established on entry to the study and SES information had previously been supplied by parents. ${ }^{18}$ (The data in the coping domain when adult height groups were separated reached significance $(p=0.005)$ on Levenes' test of homogeneity, indicating

\begin{tabular}{|c|c|c|c|c|c|c|}
\hline & \multicolumn{3}{|c|}{ Short normal participants } & \multicolumn{3}{|c|}{ Control participants } \\
\hline & $\begin{array}{l}\text { Interviewed } \\
(n=48)\end{array}$ & $\begin{array}{l}\text { Not interviewed } \\
(n=28)\end{array}$ & $p$ value & $\begin{array}{l}\text { Interviewed } \\
(n=66)\end{array}$ & $\begin{array}{l}\text { Not interviewed } \\
(n=27)\end{array}$ & $p$ value \\
\hline Recruitment height & -2.62 & -2.56 & 0.27 & -0.22 & -0.18 & 0.79 \\
\hline $\begin{array}{l}\text { Final height } \\
\text { SES (\%) }\end{array}$ & -1.86 & -1.95 & $\begin{array}{l}0.55 \\
0.078\end{array}$ & 0.08 & 0.01 & $\begin{array}{l}0.69 \\
0.93\end{array}$ \\
\hline Non-manual & $18(38)$ & $6(21)$ & & $29(44)$ & $11(41)$ & \\
\hline Manual & $27(56)$ & $18(64)$ & & $29(44)$ & $12(44)$ & \\
\hline Benefit & $3(6)$ & $4(14)$ & & $8(12)$ & $4(15)$ & \\
\hline Gender & & & 0.50 & & & 0.43 \\
\hline Female & $22(46)$ & $12(43)$ & & $30(45)$ & $11(41)$ & \\
\hline Male & $26(54)$ & $16(57)$ & & $36(55)$ & $16(59)$ & \\
\hline
\end{tabular}


that the data should not be analysed parametrically. A Kruskal-Wallis $\mathrm{H}$ test was used to analyse this data, and this comparison alone was not adjusted for gender and SES). Analyses of variance and $\chi^{2}$ tests were used to explore the possible mechanisms for significant class and gender effects on the ADAPFA domains. Patterns of behaviour in the aspects of daily living categories were compared using the $\chi^{2}$ test.

\section{RESULTS}

ADAPFA

\section{Effect of recruitment height}

Table 3 shows the means and standard deviations of the short normal and control group participants' scores on total and six domains of ADAPFA. After adjusting for gender and SES, there was no significant difference between the groups selected on recruitment height on the ADAPFA derived scores ( $\mathrm{F}=1.281, \mathrm{df}=7,104, \mathrm{p}=0.267)$. Thus recruitment height did not appear to be affecting how the participants functioned in adult roles in society. There were no significant univariate differences between the height groups after the adjustment. ADAPFA total scores, and three of the domain scores produced higher scores for short normal than average height participants, but these differences were slight, and none were significant when compared individually.

As expected, however, the covariates of gender and socioeconomic status both contributed to performance on the ADAPFA. Gender had a significant effect on the total ADAPFA score $(F=7.041, p=0.009)$ and also on the love relationships $(\mathrm{F}=4.13, \mathrm{p}=0.045)$, social contact $(\mathrm{F}=4.115$, $\mathrm{p}=0.045)$, and coping domain scores. In each instance, males scored higher than females, indicating poorer functioning. It was thought that the relation between gender and social contact domain scores may be influenced by involvement in violence, as such behaviour would result in higher scoring and males more frequently reported being involved in violence (males $37 \%$, females $17 \%, \mathrm{p}=0.064$ ). The relation between involvement in violence and problems in the social contacts domain also approached significance $(\mathrm{p}=0.061)$.

Socioeconomic status had a significant effect on total ADAPFA score $(\mathrm{F}=14.304, \mathrm{p}=0.000)$ and also on the domains of education and employment ( $F=11.199$, $p=0.001$ ), and coping. In each of these areas low socioeconomic status was associated with poorer functioning. The IQ of all participants had been obtained previously ${ }^{18}$ and since IQ is associated with social class and educational outcome, we examined the influence of IQ on the education and employment domain but found no significant effect $(\mathrm{p}=0.13)$

Table 3 Mean total and domain scores on ADAPFA for short normal and control groups, determined by childhood height, before adjustment for gender and social class

\begin{tabular}{lll}
\hline & \multicolumn{2}{l}{ Childhood height } \\
\cline { 2 - 3 } & $\begin{array}{l}\text { SN } \\
(\mathbf{n}=48)\end{array}$ & $\begin{array}{l}\mathbf{C} \\
(\mathbf{n}=66)\end{array}$ \\
\hline ADAPFA total score & $12.12(4.44)$ & $11.35(4.07)$ \\
Education and employment & $1.90(1.12)$ & $1.89(1.20)$ \\
Love relationships & $2.65(1.60)$ & $2.3(1.40)$ \\
Friendships & $2.17(1.21)$ & $1.80(1.13)$ \\
Social contacts & $2.04(1.17)$ & $2.03(1.18)$ \\
Coping & $1.79(0.85)$ & $1.97(0.86)$ \\
Negotiations & $1.77(1.22)$ & $1.47(1.08)$ \\
\hline
\end{tabular}

There were no significant interaction effects between height, class, and gender.

A similar number of short normal and control participants had a total ADAPFA score of 16 or above, which is taken as indicating some degree of personality dysfunction (SN: 10 $(21 \%), C: 11(17 \%), p=0.371)$.

\section{Effect of adult stature}

Table 4 shows the means and standard deviations of the three adult height group participants' scores on total and five of the six domains of ADAPFA. The MANCOVA results found no effect of adult height on personality functioning after adjusting for SES and gender $(\mathrm{F}=0.884$, df 14,206 , $\mathrm{p}=0.518)$. Coping domain scores were not distributed appropriately for parametric analysis, but the KruskalWallis score obtained for an unadjusted comparison was not significant either. There were no significant univariate differences between the height groups after the adjustment. Again, though, the mean total ADAPFA score was higher for the shortest adult height group, and domain scores for Friendship and Negotiation were also close to a significant difference when compared individually across the three height groups.

The patterns of significant effects of gender and SES were however the same as those found when comparing the recruitment height groups. Gender had a significant effect on total ADAPFA score $(\mathrm{F}=7.7, \mathrm{p}=0.006)$, love relationships $(\mathrm{F}=3.861, \mathrm{p}=0.052)$, social contacts $(\mathrm{F}=4.739, \mathrm{p}=0.039)$, and coping $(p=0.004)$. SES had a significant effect on total ADAPFA score $(\mathrm{F}=14.304, \mathrm{p}<0.001)$ and the education and employment domain score $(\mathrm{F}=11.199, \mathrm{p}=0.001)$. Again the percentages of participants with ADAPFA scores above the suggested cut off point of 16 for psychological dysfunction were similar across the groups ( $<2$ SD: $4(21 \%),-2$ to 0 SD: $11(18 \%),>0$ SD: $6(18 \%), p=0.948)$.

\section{Aspects of daily living}

No significant effects of either recruitment height or adult height were found on the aspects of daily living (tables 5 and 6).

\section{DISCUSSION}

In this study, childhood stature and final adult stature have not had a significant effect on the personality functioning of young adults. Though the shortest group has received slightly higher scores in some domains, the young people across the height groups interviewed have generally described similar patterns of behaviour. These results are in line with previous results from the Wessex Growth Study that short normal

Table 4 Mean (SD) total and domain ADAPFA scores for the three groups based on adult height, before adjustment for gender and social class

\begin{tabular}{llll}
\hline \multicolumn{3}{c}{ Adult height } & \\
\cline { 2 - 4 } & $\begin{array}{l}<-2 \text { SD } \\
(\mathbf{n}=19)\end{array}$ & $\begin{array}{l}-2 \text { SD to 0 SD } \\
(\mathbf{n}=61)\end{array}$ & $\begin{array}{l}>0 \text { SD } \\
(\mathbf{n}=34)\end{array}$ \\
\hline $\begin{array}{l}\text { ADAPFA total score } \\
\text { Education and }\end{array}$ & $13.05(4.08)$ & $11.59(4.13)$ & $1.06(4.42)$ \\
employment & $1.95(1.08)$ & $2.00(1.18)$ & $1.68(0.98)$ \\
Love relationships & $2.63(1.74)$ & $2.36(1.18)$ & $2.50(1.40)$ \\
Friendship & $2.32(1.20)$ & $2.00(0.90)$ & $1.59(1.05)$ \\
Social contacts & $2.32(1.20)$ & $2.00(1.06)$ & $1.94(1.13)$ \\
Coping* & $1.79(0.54)$ & $1.89(0.90)$ & $1.97(0.94)$ \\
Negotiations & $2.16(1.30)$ & $1.52(1.06)$ & $1.41(1.16)$ \\
\hline
\end{tabular}

*This comparison based on a Kruskal-Wallis analysis only, with no adjustment for gender and SES. 
Table 5 Comparisons of the percentage of short normal and control young people reporting behaviours labelled as "aspects of daily living", based on height at initial recruitment

\begin{tabular}{llll}
\hline Aspects of daily living & SN \% & Control \% & p value \\
\hline Current drug use & 23 & 32 & 0.36 \\
Drug frequency & 10 & 21 & 0.64 \\
Drinking frequently & 54 & 73 & 0.21 \\
Further education & 67 & 63 & 0.76 \\
Employment & 52 & 67 & 0.16 \\
Relationships & 52 & 55 & 0.33 \\
Parenthood & 10 & 10 & 0.68 \\
Violence severity & 4 & 15 & 0.16 \\
Victim & 8 & 8 & 0.34 \\
\hline
\end{tabular}

stature has not had a significant adverse effect on functioning during childhood and early adolescence. ${ }^{16-18}$

It has been suggested in the literature that adults of short stature might function differently in the areas of education, employment, love relationships, and friendships, ${ }^{9-14}$ but no significant differences in these areas were found. The Wessex Growth Study is the first longitudinal study of the effects of stature in a community sample and thus may show a truer picture of the effects of stature on daily living than previous reports which have predominantly been cross sectional, or based on mixed diagnostic group or clinic referred samples. The participants were identified solely on the basis of their height at school entry and none had been referred to a growth clinic, or had any concern expressed about them. Crucially also their age at recruitment reflected the time when treatment decisions (relating to short stature) are being made. The outcomes described in this paper therefore imply that an increase in height per se for these participants would not necessarily have contributed any more to their quality of life. Clearly there may still be referrals to growth clinics, but perhaps such clinics could review psychotherapeutic alternatives to medical treatment for those who do express height related concerns (usually on behalf of others: their children). In some cases psychological concerns might already exist before referral to a growth clinic, suggesting perhaps that a form of psychological screening might be relevant, though this is not a direct indication from the study.

The data from this study do, however, confirm that personality functioning is influenced by both gender and SES. The relation between personality and gender is not surprising. Costa et al have shown the cultural stability of male and female personality traits, ${ }^{27}$ and previous studies using the parent measure of the ADAPFA, the ADPFA, have reported gender effects. ${ }^{20}$ The females in our study were more likely than males to be functioning independently and to be in a love relationship and less likely to have problems in the social contacts domain. There are several explanations for these findings. First, even in European cultures such as ours, social role functioning is consistent with gender stereotypes with women still performing the majority of household tasks. ${ }^{28}$ It is possible that gender differences in the coping domain were attributable simply to the females' greater involvement in this area as much of the rating in this domain rests on the participants' ability to feed and clothe themselves and manage their finances. Second, the participants were assessed when they were 18-20 years old, the youngest age group for which the ADAPFA is recommended. It is possible that, in the domain of love relationships, a gender bias is inherent when used with such a group. Further studies including 18-20 year olds are needed to substantiate this hypothesis. Third, the domain of social contacts is influenced by involvement in violence. Reports of violent acts increase scores and in our study, males, short and control, tended to report involvement in acts of violence more often than the females.

The young adults in our study who were from a lower SES were more likely to experience problems in education, employment, and day to day living tasks such as managing finances. Others have also found that SES affects both personality functioning ${ }^{23}$ and education. ${ }^{24}$ IQ did not explain the relation between SES and the education and employment domain scores, possibly because participants with lower IQs were performing adequately in the employment domain. The finding that SES but not IQ was associated with scoring on the education and employment domain suggests that participants with lower SES were less likely to achieve their potential in these areas. Indeed research shows that lower childhood SES can have negative effects on later adult life. ${ }^{29}$

The results of this study seem to reflect untroubled development for short normal participants. However, it is of concern to note that a significant number of young adults, both short and control, reported involvement in high risk taking behaviour such as drug use and severe violence (table 5), and that $10 \mathrm{SN}$ and $11 \mathrm{C}$ participants showed some degree of personality dysfunction. Neither childhood nor adult short stature appears to be a contributory factor. While neither recruitment or adult height can be seen as a contributory factor, further analysis of the specific determinants here will be reported separately. Similarly the interaction of pubertal timing with these life experiences is also of interest, perhaps particularly in a study of growth, and again possible relations here are being examined.

Some limitations to the findings of the present study are evident. Firstly, as described in the methods section of the 170 participants who remained available for this phase of the study, only 114 participants could be interviewed. These participants were however found to be representative of the total sample available for this phase of the research.

\begin{tabular}{|c|c|c|c|c|}
\hline Aspects of daily living & Short \% & Average \% & Above average \% & $p$ value \\
\hline Current drug use & 16 & 31 & 30 & 0.70 \\
\hline Drug frequency & 0 & 22 & 15 & 0.67 \\
\hline Drinking frequently & 42 & 67 & 72 & 0.27 \\
\hline Further education & 63 & 62 & 70 & 0.93 \\
\hline Employment & 47 & 61 & 67 & 0.26 \\
\hline Relationships & 42 & 61 & 45 & 0.29 \\
\hline Parenthood & 10 & 12 & 6 & 0.77 \\
\hline Violence severity & 5 & 12 & 9 & 0.72 \\
\hline Victim & 5 & 12 & 3 & 0.33 \\
\hline
\end{tabular}


Secondly, the height SD of a proportion of the short normal participants is now above the original centile band defining short stature. Such a phenomenon has been reported in other studies. ${ }^{30}$ Few, however, had a height above the 25 th centile and our results are from a sample of young adults who for the majority of their lives have been shorter than their peers, having been recruited at the critical age for treatment decisions.

In summary, no significant differences in personality functioning or aspects of daily living were found which could be attributable to height. This should not be interpreted as indicating that people with short stature will not experience problems in their development, but that they are no more likely to do so than those who are taller. This study is unique as it reports on the effect of both childhood height on adult functioning and the effect of adult height on functioning in the same sample

\section{Authors' affiliations}

F Ulph, P Betts, J Mulligan, R J Stratford, University of Southampton, UK

\section{REFERENCES}

1 Brook CGD. Growth hormone: panacea or punishment for short stature? BMJ 1997;315:692-3.

2 Kelnar CJH, Albertsson-Wikland K, Hintz RL, et al. Should we treat children with idiopathic short stature? Workshop held in St.-Paul-de-Vence, France, 18-19 April 1999. Horm Res 1999:52:150-7.

3 Saenger P. Use of growth hormone in the treatment of short stature: boon or abuse? Endocrinology 1991;12:355-62.

4 Samaras TT, Elrick H, Storms LH. Height, health and growth hormone. Acta Paediatr 1999;88:602-9.

5 Voss LD. Short normal stature and psychosocial disadvantage: a critical review of the evidence. J Pediatr Endocrinol Metab 2001;14:701-1 1.

6 Sandberg DE, Brook AE, Campos,S. Short stature: a psychosocial burden requiring growth hormone therapy. Pediatrics 1994;9:832.

7 Voss L. Short stature: does it matter? J Med Screen 1995:2:130-2.

8 Kranzler JH, Rosenbloom AL, Proctor B, et al. Is short stature a handicap? A comparison of psychosocial functioning of referred and non-referred children with normal short stature and children with normal stature. J Pediatr 2000;126:96-102.

9 Wake M, Coghlan D, Hesketh K. Does height influence progression through primary school grades? Arch Dis Child 2000;82:297-301.

10 Hensley WE, Cooper R. Height and occupational success: a review and critique. Psychol Rep 1987;60:843-9.
11 Sargent JD, Blanchflower DG. Obesity and stature in adolescence and earnings in young adulthood. Arch Pediatr Adolesc Med 1994;148:681-7.

12 Martel LF, Biller HB. Stature and stigma: the biopsychosocial development of short males. Lexington, MA: DC Heath \& Co., 1987.

13 Gillis JS, Avis WE. The male-taller norm in mate selection. Personality Social Psychology Bulletin 1980;6:396-401

14 Sheppard JASAJ. Attractiveness and height: the role of stature in dating preference, frequency of dating and perceptions of attractiveness. Personality and Social Psychology Bulletin 1989;15:617-27.

15 Stratford RJ, Mulligan J, Downie AB, et al. Threats to validity in the longitudinal study of psychological effects: the case of short stature. Child Care Health Dev 1999;25:401-19.

16 Voss LD, Mulligan J. The short normal child in school: self-esteem, behaviour, and attainment before puberty (The Wessex Growth Study). In: Stabler B, Underwood LE, eds. Growth, stature, and adaptation. Chapel Hill: University of North Carolina, 1994.

17 Voss L, Bailey BJR, Mulligan J, et al. Short stature and school performanceThe Wessex Growth Study. Acta Paediatr Scand Suppl 1991;377:29-31.

18 Downie AB, Mulligan J, Stratford RJ, et al. Are short normal children at a disadvantage? The Wessex Growth Study. BMJ 1997;314:97-100.

19 Naughton M, Oppenhein A, Hill J. Assessment of personality functioning in the transition form adolescence to adult life: preliminary findings. Br J Psychiatry 1996;168:33-7.

20 Hill J, Fudge $\mathrm{H}$, Harrington $\mathrm{R}$, et al. The Adult Personality Functioning Assessment (ADAPFA): factors influencing agreement between subjects \& informant. Psychosocial Medicine 1995;25:263-75.

21 Downie AB, Mulligan J, McCaughey E, et al. Psychological response to growth hormone treatment in short normal children. Arch Dis Child 1996;75:32-5.

22 Freeman JV, Cole TJ, Chinn S, et al. Cross sectional stature \& weight reference curves for the UK, 1990. Arch Dis Child 1990;73:17-24.

23 Piko B, Fitzpatrick KM. Does class matter? SES and psychological health among Hungarian adolescents. Soc Sci Med 2001;53:817-30.

24 James R. Participation disadvantage in Australian higher education: an analysis of some effects of geographical location and socioeconomic status. Higher Education $2001: 42: 455-72$.

25 Golomb M, Fava M, Abraham M, et al. Gender differences in personality disorders. Am J Psychiatry 1995; 152:579-82.

26 Grillo CM, Becker DF, Walker ML, et al. Gender differences in personality disorders in psychiatrically hospitalised young adults. J Nerv Ment Dis 1996; 184:745-7.

27 Costa PT, Terracciano A, McCrae RR. Gender differences in personality traits across cultures: robust and surprising findings. J Pers Soc Psychol 2001;81:322-31.

28 Bond S, Sales J. Household work in the UK: an analysis of the British Household Panel Survey 1994. Work Employment and Society 2001;15:233-50.

29 Bradley RH, Corwyn RF. Socioeconomic status and child development. Annu Rev Psychol 2002;53:371-99.

30 Parkin M. Epidemiology of growth failure. In: Wilkin TJ, ed. Growth in childhood. Harwood Academic Publishers, 1989:47-9.

\section{ARCHIVIST}

\section{Steroids for Kawasaki disease}

andard initial treatment for Kawasaki disease in the USA is a single dose of

S intravenous immunoglobulin (IVIG) $2 \mathrm{gm} / \mathrm{kg}$ plus aspirin $80-100 \mathrm{mg} / \mathrm{kg} / \mathrm{day}$. The role of steroid treatment is controversial. Steroids have been used either as initial therapy or as rescue therapy after failure of IVIG and aspirin. Most studies have documented clinical improvement with steroids but there has been a suggestion that the risk of coronary abnormalities might be increased. A small trial in Boston, Massachusetts of pulsed-dose intravenous methylprednisolone added to IVIG and aspirin as initial treatment has confirmed that clinical resolution is quicker with steroid therapy (Robert P Sundel and colleagues. Journal of Pediatrics 2003;142:611-6, see also editorial, ibid 601-3).

Thirty-nine children were randomised on day 4-10 (median, day 7) of illness to IVIG $2 \mathrm{gm} / \mathrm{kg}$ over 10 hours plus oral aspirin either with or without pulsed-dose intravenous methylprednisolone, $30 \mathrm{mg} / \mathrm{kg}$ prior to the IVIG. The methyl prednisolone group had a shorter duration of fever after starting treatment ( 1.0 vs 1.9 days), shorter hospital stay (1.9 vs 3.3 days), and lower ESR and C-reactive protein at 6 weeks. Coronary artery dimensions after treatment did not differ significantly between the two groups but numbers were small.

The authors of this paper call for a large, multicentre trial. An editorialist advises that in the meantime there is not enough evidence to justify the routine use of steroids in primary therapy. For rescue therapy he also considers the evidence to be inadequate but prefers to use a second, or even a third, dose of IVIG if necessary. 